\title{
Inequalities in maternal health care utilization in Benin: a population based cross-sectional study
}

\author{
Sanni Yaya ${ }^{1 *} \mathbb{D}$, Olalekan A. Uthman², Agbessi Amouzou ${ }^{3}$, Michael Ekholuenetale ${ }^{4}$ and Ghose Bishwajit ${ }^{1}$
}

\begin{abstract}
Background: Ensuring equitable access to maternal health care including antenatal, delivery, postnatal services and fertility control methods, is one of the most critical challenges for public health sector. There are significant disparities in maternal health care indicators across many geographical locations, maternal, economic, sociodemographic factors in many countries in sub-Sahara Africa. In this study, we comparatively explored the utilization level of maternal health care, and examined disparities in the determinants of major maternal health outcomes.
\end{abstract}

Methods: This paper used data from two rounds of Benin Demographic and Health Survey (BDHS) to examine the utilization and disparities in factors of maternal health care indicators using logistic regression models. Participants were 17,794 and 16,599 women aged between15-49 years in 2006 and 2012 respectively. Women's characteristics were reported in percentage, mean and standard deviation.

Results: Mean $( \pm$ SD) age of the participants was $29.0( \pm 9.0)$ in both surveys. The percentage of at least 4 ANC visits was approximately $61 \%$ without any change between the two rounds of surveys, facility based delivery was $93.5 \%$ in 2012, with 4.9\% increase from 2006; postnatal care was currently $18.4 \%$ and contraceptive use was estimated below one-fifth. The results of multivariable logistic regression models showed disparities in maternal health care service utilization, including antenatal care, facility-based delivery, postnatal care and contraceptive use across selected maternal factors. The current BHDS showed age, region, religion were significantly associated with maternal health care services. Educated women, those from households of high wealth index and women currently working were more likely to utilize maternal health care services, compared to women with no formal education, from poorest households or not currently employed. Women who watch television (TV) were $1.31(\mathrm{OR}=1.31 ; 95 \%$ $\mathrm{Cl}=1.13-1.52), 1.69(\mathrm{OR}=1.69 ; 95 \% \mathrm{Cl}=1.20-2.37)$ and $1.38(\mathrm{OR}=1.38 ; 95 \% \mathrm{Cl}=1.16-1.65)$ times as likely to utilize maternal health care services after adjusting for other covariates.

Conclusion: The findings would guide stakeholders to address inequalities in maternal health care services. More so, health care programmes and policies should be strengthened to enhance accessibility as well as improve the utilization of maternal care services, especially for the disadvantaged, uneducated and those who live in hard-toreach rural areas in Benin. The Benin government needs to create strategies that cover both the supply and demand side factors at attain the universal health coverage.

Keywords: Antenatal care, Postnatal care, Contraceptive use, Institutional delivery, Inequalities, Benin, Demographic and health survey, Cross-sectional study

\footnotetext{
* Correspondence: sanni.yaya@uOttawa.ca

${ }^{1}$ School of International Development and Global Studies, University of

Ottawa, Ottawa, Canada

Full list of author information is available at the end of the article
}

(c) The Author(s). 2018 Open Access This article is distributed under the terms of the Creative Commons Attribution 4.0 International License (http://creativecommons.org/licenses/by/4.0/), which permits unrestricted use, distribution, and reproduction in any medium, provided you give appropriate credit to the original author(s) and the source, provide a link to the Creative Commons license, and indicate if changes were made. The Creative Commons Public Domain Dedication waiver (http://creativecommons.org/publicdomain/zero/1.0/) applies to the data made available in this article, unless otherwise stated. 


\section{Background}

The steps towards achieving the third United Nations (UN) Sustainable Development Goals (SDGs), to reduce maternal morbidity and mortality and achieve universal health coverage to include access to essential health care services by 2030 have been a great issue in developing countries, even with the existence of health care interventions. Though there are numerous health care implementation projects to promote safe motherhood worldwide, maternal morbidity and mortality remain a notable hitch in health care programme and policy making particularly in low-income countries. In spite of the vast efforts by the global community to lessen the burden of mortality as a result of pregnancy and delivery, the rate of death due to pregnancy related complications is worrisome [1]. Developing countries have been reported to account for about $99 \%$ of the global maternal mortality, while sub-Saharan Africa (SSA) countries record approximately $62 \%$ and having Maternal Mortality Ratio (MMR) of 510 maternal deaths per 100,000 live births $[2,3]$. The challenge of unfair distribution of health care services is gaining global attention in the area of public health, with evidence of the disadvantaged sections of the society, having worst health conditions [1]. Like other sub-Saharan countries, Benin is having an unfair share in maternal health care. A country with Total Fertility Rate (TFR) of 5.3, is ranked the 34th in the world with maternal death [4].

Inadequate of access to antenatal, intrapartum and postnatal health care services are among the prominent reasons for high maternal and child morbidities and mortalities in SSA and the world at large $[5,6]$. Maternal health care services continue to be important indicators for monitoring the improvement of maternal health outcomes, as well as maternal mortality. In addition, antenatal care, institutional health delivery with skilled birth attendant, and postnatal care strengthen prompt management and treatment of pregnancy related complications to reduce maternal mortality. Besides the benefits of institutional based delivery in the prevention of maternal death, more women give birth utilizing alternative places such as home and Traditional Birth Attendants (TBA) who are not knowledgeable in modern obstetric care [7]. One of the major pillars of the Safe Motherhood Initiative is antenatal care, which helps to provide interventions that are essential for positive pregnancy outcomes [8]. World Health Organization (WHO) remark that receiving antenatal care not less than four times increases the odds of receiving valuable health care promotion and preventive maternal health care interventions during antenatal visits $[9,10]$. Furthermore, family planning is also a vital indicator of the Safe Motherhood Initiative to reduce pregnancy related complications and death in developing countries [10].
Essential emergency obstetric health care services are required to access key equitable resources across regions, socio-economic strata and geographical locations [11]. Maternal health care services encompass a wide range of clinical procedures and care provided to women during pregnancy. As a matter of necessity, all pregnant women should have access to quality antenatal care regardless of their economic, cultural, geographical and social background. Interestingly, antenatal care performs a crucial role in ensuring a healthy baby and mother during pregnancy and after delivery. This care is given to pregnant women to optimize quality health outcomes, such as normal birth weight, reduction in maternal and child death and low postpartum anemia [12]. More so, countries that have achieved success in improving maternal health care services and reducing maternal morbidity mortality overall, are still faced with the challenges of large inequities among various sections of the populations. The groups of women that are disadvantaged tend to have more morbidity and mortality, and inadequate access to safe motherhood services, acceptable and affordable health care services to enhance safe pregnancy and delivery [13]. Efforts have been made to reduce health inequities across all facets of the populations, on subnational, national and global levels, and ensure equal opportunities to all members of communities to achieve good health [14]. However, most health care systems are inequitable, benefiting the wealthy than the underprivileged [15].

There are significant disparities in maternal health care indicators across many geographical locations, maternal, economic, socio-demographic factors in many developing countries [16]. Whereas equity has been indicated as a prominent target within the health sectors, huge disparities exist in coverage of maternal and child health care services between the well-off and disadvantaged in low income countries. The inequalities and inequities across various strata of the society have become key determinants of maternal and child health $[17,18]$. Obtaining equal access to maternal health care including antenatal, delivery and postnatal services, is one of the most critical concerns in public health programmes and policies shared in virtually everywhere in the world, and demands that women with the same maternal needs should receive the same access to health care services [19].

In this study, inequities in the determinants of major maternal health outcomes including antenatal care, institutional delivery with skilled birth attendance and utilization of modern contraception were examined using Benin Demographic and Health Survey (BDHS) dataset. We presented comparative analyses of the outcome variables in two separate BDHS to assess disparities in the utilization of these services. 


\section{Methods}

\section{Data extraction}

Data for this study were derived from two rounds of Demographic and Health Survey in Benin that provided information on antenatal care, institutional delivery and contraceptive use. The datasets have one record for every eligible woman as defined by the household schedule. The questionnaire contains all the data collected from the individual woman for whom information on antenatal care, delivery and contraceptive usage and some variables from the household were elicited. The 2006 and 2012 Benin Demographic and Health Survey (BDHS) data contains 17,794 and 16,599 cases (units of analysis), which in this file is the woman. BDHS performed cross-sectional analyses using nationally representative data, to collect information on demographic, health, and nutrition indicators. The survey is majorly funded by the United States Agency for International Development (USAID). The two rounds of BDHS utilized a multi-stage, stratified sampling design, with households as the sampling unit. Within each sample household, all eligible women were interviewed [20].

\section{Outcome variables}

In this study, we used four outcome measures of maternal health care utilization extracted from the BDHS. Firstly, we derived the; "number of antenatal care (ANC) visits during pregnancy", this was grouped as 4 or more ANC visits vs below 4 ANC visits. ANC visits is a measure of skilled pregnancy care received by women during most recent pregnancy. Secondly, we extracted the "place of delivery (home vs health facility)". This was measured as a binary outcome for 1 , if a woman delivered in a health facility (where skilled delivery attention is available) and 0 , if otherwise. In addition, postnatal care was measured by "respondents health's checked after discharge/delivery at home" Lastly, women's "contraceptive use"; was obtained as binary indicator taking 1 if the "woman ever used a contraceptive method" and 0 , if otherwise.

\section{Explanatory variables}

The utilization of ANC visits, facility-based delivery and contraceptive use are known to depend on a set of determinants, such as demographic, economic, other proximate and social factors. Empirical literature on the factors pertinent to maternal health care services basically helped to select the variables of study. These variables age of individual woman (15-19, 20-24, 25-29, 30-34, 35-39, 4044 and 45-49 year), geographical region (Alibori, Atacora, Atlantique, Borgou, Collines, Couffo, Donga, Littoral, Mono, Queme, Plateau and Zou), type of residence (rural vs urban). Educational attainment was categorized as those having no formal education, primary, secondary and higher education. Religious beliefs included; Christianity,
Islam, traditional and other religion, while access to health information was measured using frequency of reading newspaper or magazine, listening to radio and watching TV. The wealth scores is obtained by principal components analysis, based on a list of household assets as specified by DHS, which include, number of household members, wall and roof materials, floor types, access to potable water and sanitation, type of cooking fuel, ownership of television, radio, motorcycle, refrigerator amongst others. Based on the weighted wealth scores, households were grouped into five wealth quintiles; poorest, poorer, middle, richer and richest. Furthermore, parity was measured by the number of children ever born by each individual woman; categorized as 1-4 and > 4 children.

\section{Ethical considerations}

We did the analyses using publicly available data from demographic health surveys. Ethical procedures were the responsibility of the institutions that commissioned, funded, or managed the surveys. All DHS surveys are approved by ICF international as well as an Institutional Review Board (IRB) in respective country to ensure that the protocols are in compliance with the U.S. Department of Health and Human Services regulations for the protection of human subjects.

\section{Statistical analysis}

Summary statistics including percentage and means ( \pm standard deviation) were used to examine the distribution of socio-demographic, economic distal and proximate maternal characteristics. To adjust for data representation, we used complex survey module (svyset) for all analyses to account for clustering, stratification and sample weight. In addition, the percentages of outcome variables were presented in bar chart. The factors associated with ANC visits, facility-based delivery, postnatal care and contraceptive use were examined using logistic regression models. The bivariate analysis conducted to examine the factors that were added in the multivariable regression models involved a simple regression with each explanatory variable. Therefore, factors, which were statistically significant in the crude regression models, were added in the multivariable regression models to adjust for possible confounders. An $\alpha$ level of 0.05 was considered statistically significant. All analyses were conducted using STATA 14.0.

\section{Results}

\section{Sample characteristics}

In this study, the characteristics of respondents were explored for 2006 and 2012 respectively. The mean ages of respondents were similar $(29.0 \pm 9.1 / 9.0)$ between the years of survey. The basic socio-demographic characteristics of the respondents were presented in Table 1. 
Table 1 Characteristics of respondents. Benin DHS 2006-12

\begin{tabular}{clllll}
\hline Variable & 2006 & & & 2012 & \\
\cline { 2 - 3 } & $n(17,794)$ & $\%$ & & $n(16,599)$ & $\%$ \\
\hline Age (Mean \pm SD) & $29.0 \pm 9.1$ & & $29.0 \pm 9.0$ & \\
$15-19$ & 3036 & 17.1 & 2922 & 17.6 \\
$20-24$ & 3117 & 17.5 & 2820 & 17.0 \\
$25-29$ & 3640 & 20.5 & 3147 & 19.0 \\
$30-34$ & 2801 & 15.7 & 2720 & 16.4 \\
$35-39$ & 2151 & 12.1 & 2185 & 13.2 \\
$40-44$ & 1626 & 9.1 & 1667 & 10.0 \\
$45-49$ & 1423 & 8.0 & 1138 & 6.9
\end{tabular}

Region

$\begin{array}{lllll}\text { Alibori } & 1197 & 6.7 & 1000 & 6.0 \\ \text { Atacora } & 1506 & 8.5 & 1476 & 8.9 \\ \text { Atlantique } & 1988 & 11.2 & 1866 & 11.2\end{array}$

$\begin{array}{lllll}\text { Borgou } & 1535 & 8.6 & 1323\end{array}$

$\begin{array}{lllll}\text { Collines } & 1234 & 6.9 & 1256 & 7.6\end{array}$

Couffo

1530

$8.6 \quad 1225$

Donga

893

Littoral

1831

5.0

Mono

1196

Quémé

2142

Plateau

Zou

862

1880

Type of place of residence

Urban

7471

Rural

10,323$$
42.0
$$$$
58.0
$$

Educational attainment

No formal education

Primary

11,577

$$
65.1
$$

$$
19 .
$$$$
14.6
$$

Higher

2595

Religion

Read newspaper/magazine

Listen to radio

Watch TV

\section{Christianity}

Islam

Traditional

Others

Yes

No

Yes

No

14,499

Yes

No

9484

3878

3178

1210

1701

15,957

$$
9.6
$$$$
90.4 \quad 14,459
$$

$53.4 \quad 9226$

$21.8 \quad 3919$

$17.9 \quad 2284$

$6.8 \quad 1170$

(

$81.7 \quad 10,525$
7070

17.6

17.0

19.0

16.4

13.2

0.0

6.9

6.0

8.9

11.2

8.0

7.6

7.4

5.7

11.7

11.7

6.3

10.9

6.3

10.0

42.6

57.4

57.4

62.6

16.7

19.4

1.4

55.6

23.6

13.8

7.0

12.9

87.1

63.4

63.4

36.6

45.5

54.5

\begin{tabular}{|c|c|c|c|c|}
\hline \multirow[t]{2}{*}{ Variable } & \multicolumn{2}{|l|}{2006} & \multicolumn{2}{|l|}{2012} \\
\hline & $n(17,794)$ & $\%$ & $n(16,599)$ & $\%$ \\
\hline \multicolumn{5}{|l|}{ Wealth index } \\
\hline Poorest & 3357 & 18.9 & 3139 & 18.9 \\
\hline Poorer & 3347 & 18.8 & 3274 & 19.7 \\
\hline Middle & 3448 & 19.4 & 3433 & 20.7 \\
\hline Richer & 3753 & 21.1 & 3511 & 21.2 \\
\hline Richest & 3889 & 21.9 & 3242 & 19.5 \\
\hline \multicolumn{5}{|l|}{ Parity } \\
\hline $1-4$ & 8379 & 60.7 & 8377 & 66.9 \\
\hline$>4$ & 5435 & 39.3 & 4145 & 33.1 \\
\hline \multicolumn{5}{|c|}{ Women decision making power } \\
\hline Low & 4140 & 35.1 & 2534 & 35.4 \\
\hline Moderate & 7664 & 64.9 & 2741 & 38.2 \\
\hline High & & & 1892 & 26.4 \\
\hline \multicolumn{5}{|c|}{ Currently working } \\
\hline Yes & 14,114 & 79.6 & 10,643 & 64.1 \\
\hline No & 3628 & 20.4 & 5956 & 35.9 \\
\hline \multicolumn{5}{|c|}{ Sex of household head } \\
\hline Male & 14,353 & 80.7 & 13,326 & 80.1 \\
\hline Female & 3441 & 19.3 & 3273 & 19.7 \\
\hline
\end{tabular}

Table 1 Characteristics of respondents. Benin DHS 2006-12 (Continued)

Prevalence of maternal health care utilization.

In this study, four outcomes were measured namely; antenatal care of at least 4 visits, facility-based delivery, postnatal care and utilization of contraceptive methods. The percentage of 4 or more antenatal visits was $61.4 \%$ in 2006 , and $61.1 \%$ in 2012 , which showed that there was no increase in the level of antenatal care visits over time. Facility-based delivery was reported as $88.6 \%$ in 2006 which had $4.9 \%$ increase by 2012. Postnatal care $15.2 \%$ in 2006, but increased to $18.4 \%$ in 2012 . Further, the percentage of contraceptive use was $17.2 \%$ in 2006 , however reduced to $14 \%$ in 2016 (see Fig. 1 for details).

The results showed that women aged 35-49 years had increase in the odds of facility-based delivery, compared to women aged 15-19 years. Further, women aged 4549 years had $45 \%$ significant reduction in the odds of contraceptive use, compared to women aged $15-19$ years after adjusting for other covariates $(\mathrm{OR}=0.55$; $95 \% \mathrm{CI}=$ 0.33-0.93). Also, geographical region was significantly associated with ANC visits, facility-based, postnatal care and contraceptive use. Rural women had $17 \%$ reduction in the odds of contraceptive use, compared to the urban women after adjusting for other covariates $(\mathrm{OR}=0.83$; $95 \% \mathrm{CI}=0.70-0.98)$. Educated women were more likely to utilize ANC visits, facility-based and postnatal care, 


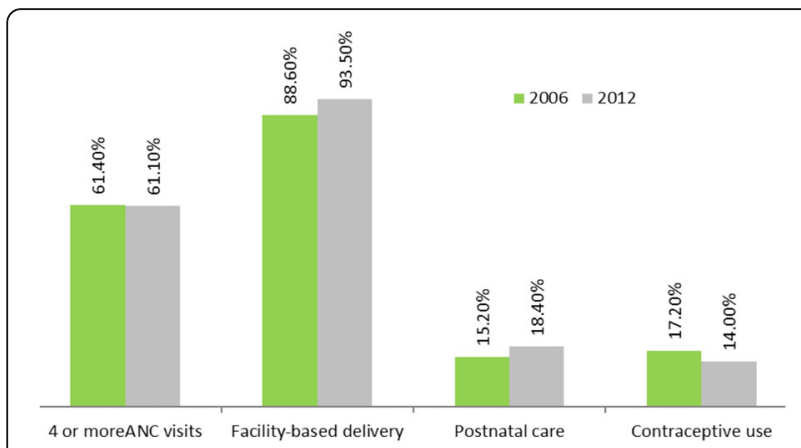

Fig. 1 Prevalence of antenatal care, contraceptive use and facility-based delivery among women of reproductive age in Benin

compared to women with no formal education after adjusting for other covariates.

Women with higher wealth index had significant increase in the odds of adequate ANC visits, facility-based delivery and contraceptive use. Number of children ever born was significantly associated with maternal health care services; women who had above 4 children had significant reduction in adequate ANC visits and facility-based delivery respectively, compared to women who had 1-4 children (ANC- OR $=0.71 ; 95 \% \mathrm{CI}=0.61-0.82$; facility-based delivery- $\mathrm{OR}=0.59 ; 95 \% \mathrm{CI}=0.48-0.72$ ). Notwithstanding, women who had above 4 children were 1.48 times as likely to have contraceptive use, compared to women who had $1-4$ children $(\mathrm{OR}=1.48 ; 95 \% \mathrm{CI}=1.27-1.71)$. Women with moderate decision-making power were 1.26 times as likely to have contraceptive use, compared to women with low decision-making power. Also, women from female headed households were 1.58 times more likely to utilize facility-based delivery, compared to women from male headed households $(\mathrm{OR}=1.58$; 95\% CI $=1.18-2.11)$. See Table 2 for details.

For 2012, women aged 45-49 years had higher odds of facility-based, compared to women aged 15-19 years after adjusting for other covariates. Respondents aged 35-44 years also had increase in the odds of contraceptive use, compared to those aged 15-19 years. The region and religion of respondents was significantly associated with adequate ANC visits, facility-based delivery, postnatal care and contraceptive use. The respondents with high decision-making power were 1.47 times as likely to have facility-based delivery, compared to women with low decision-making power after adjusting for other covariates $(\mathrm{OR}=1.47 ; 95 \% \mathrm{CI}=1.03-2.10)$. Further, women who were currently working or employed had higher odds of ANC visits, facility-based delivery and contraceptive use. Women from female headed households were 2.04 times as likely to have facility-based delivery, compared to other counterpart after adjusting for other covariates $(\mathrm{OR}=$ 2.04; 95\% CI $=1.14-3.67)$.

\section{Discussion}

Main findings

This study has become the foremost to explore and examine prominent indicators of maternal health care service utilization in Benin, and thus utilized two rounds of nationally representative data set from 2006 and 2012 surveys. The main outcome measures under study were ANC visits, institutional delivery, postnatal care and contraceptive use among women of reproductive age. The prevalence of ANC at least 4 or more visits, facility-based delivery, postnatal care and contraceptive use among women of reproductive age were relatively the same in both rounds of survey. The estimates are consistent with literature from other sub-Saharan Africa countries where maternal health care indicators need more improvement [21-23]. Furthermore, socio-demographic, economic and proximate determinants were the main predictors of maternal healthcare services. Age, geographical region, place of residence, level of education, religious beliefs, use of media, wealth index and parity were significant predictors for the disparity in access to skilled pregnancy care and fertility control [22-25].

In addition, this study found disparities in the demographic, social, economic and proximate factors associated with the utilization of maternal health care services. The SDGs are known to support reduction in inequalities and ensure health for all populations. In the light of the above, beyond the utilization of maternal health care, also to reach the most disadvantaged group of the women, vis-a-vis the use of maternal care services must be considered to achieve the set goals [26]. The findings in this study showed that women with lower educational level, inaccessibility of the media (newspaper, radio and television), low economic class, rural dwellers amongst others are less likely to utilize maternal healthcare services. This revealed disproportionate share of maternal healthcare services by certain class of people despite of the high demand. The results were in line with previous studies in other countries [27-30].

Though there are interventions to improve coverage of maternal and child health care services in sub-Saharan Africa, the disparity in access and use by several factors such as place of residence, use of media, geographical region, educational attainment, age of women and wealth quintile amongst others has remained persistently high in the two rounds of data utilized [30, 31]. Explaining differentials in accessing maternal and reproductive care services is a critical issue, because several other contributory factors, including distance, cultural beliefs or practices, health care seeking behavior, affordability and need for services must also be considered [31]. The findings of this study were consistent with previous studies that reported that improvement in economic status was connected to better use of maternal health 


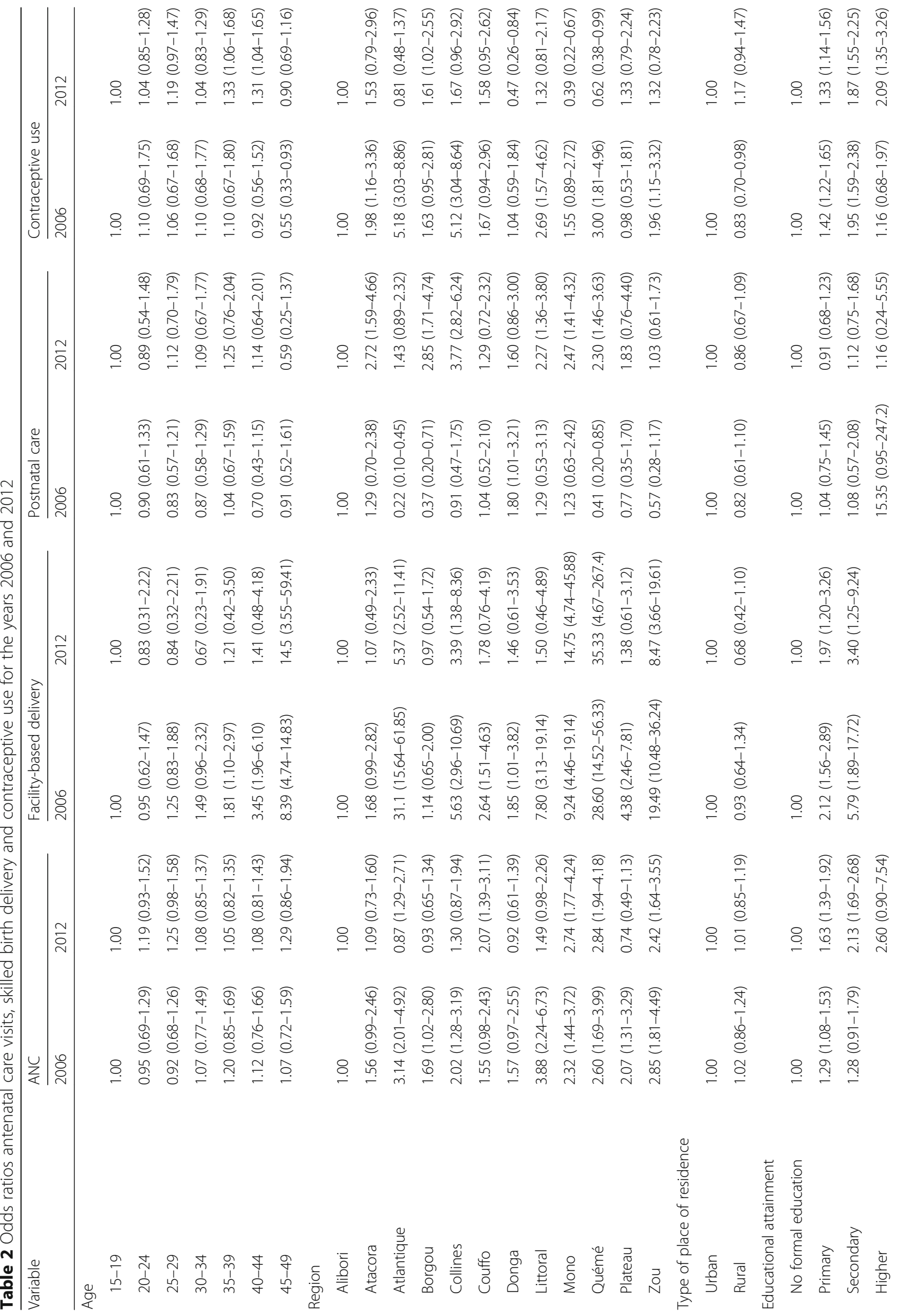




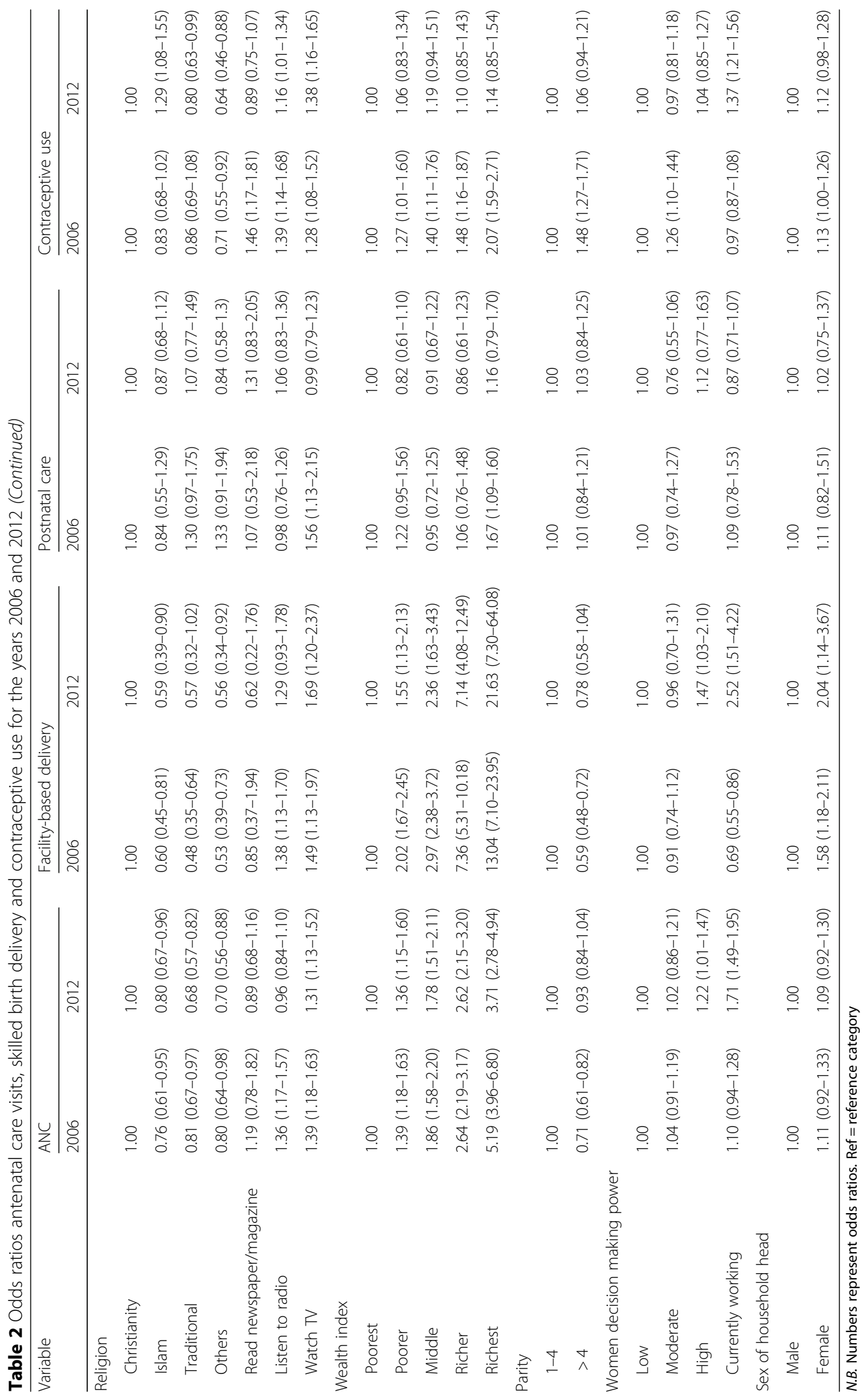


services [10]. Again, religious beliefs and residency usually indicate cultural background and influence norms, values and beliefs in relation to women's status, service use and childbirth. Previous studies have reported low levels of maternal healthcare utilization among ethnic minority women in rural areas [32-34]. Also, maternal decision-making power was associated with health care behaviors. Women's empowerment enhance the knowledge and need of health care and awareness of services which can improve through behavior change communication and increase the ability of a woman to have positive health care-seeking behavior. Overall, our study is consistent with the findings from a review of numerous studies in developing countries that women's empowerment is positively associated with the use of maternal health care services [35].

\section{Strengths and limitations}

The main strength of this study is that it leverages on nationally representative data collected through a consistent methodology in 2006 and 2011-12. In addition, this is the foremost nationwide analyses that explores antenatal visits, facility-based delivery, postnatal and contraceptive utilization in Benin, and as such could serve as benchmark and stimulus for further nationwide studies on related subjects. Nonetheless, cross sectional data are unable to sufficiently establish causality, again due to self-report method of eliciting information from respondents, there could be possibility of recall bias which could affect the level of utilization of maternal health care services reported in this study.

\section{Conclusion}

This study has identified the importance of vital maternal care services and associated socio-demographic, economic and proximate factors disparities against the backdrop of poor maternal health indicators in Benin. The findings showed consistent differentials in the use of key maternal health services, such as ANC visits, facility-based delivery, postnatal care and contraceptive use, in favor of women in urban, educated, high economic status and use of media. Though the study revealed disparities in selected determinants of maternal care services in Benin, however, there are other factors such as environmental conditions, governance, culture, infrastructure and availability of medical equipment and personnel that play vital role in reduction of these differences. Hence, the findings would guide stakeholders in health care system to address the unequal access in health care services. As we strive for universal health coverage, health care interventions, programmes and policies should be strengthened to enhance maternal care services utilization, and tackle the disparities in the utilization of maternal care services, especially for the disadvantaged who live in hard-to-reach rural areas in Benin.
The Benin government needs to create strategies that cover both the supply and demand side interventions, specifically to reach the uneducated, living in remote areas with inadequate resources to have access to health care services. Such strategy must go beyond any specific intervention for maternal health care to accommodate a wider developmental agenda and human capital development.

\section{Abbreviations \\ ANC: Antenatal care; DHS: Demographic Health Survey; IRB: Institutional Review Board; MMR: Maternal Mortality Ratio; SDGs: Sustainable \\ Development Goals; SSA: Sub-Saharan Africa; TBA: Traditional Birth Attendant; USAID: United States Agency for International Development; WHO: World Health Organization}

\section{Acknowledgments}

The authors thank the MEASURE DHS project for their support and for free access to the original data.

Funding

The authors have no support or funding to report.

Availability of data and materials

Data for this study were sourced from Benin Demographic and Health surveys (DHS) and available here: https://dhsprogram.com/what-we-do/ survey/survey-display-420.cfm and here: https://dhsprogram.com/what-wedo/survey/survey-display-491.cfm

\section{Authors' contributions}

SY and ME contributed to the study design, the review of literature, and analysis of literature, manuscript conceptualisation and preparation. OU, AA and GB critically reviewed the manuscript for its intellectual content. SY had final responsibility to submit for publication. All authors read and approved the final manuscript.

\section{Ethics approval and consent to participate}

Ethics approval for this study was not required since the data is secondary and is available in the public domain. More details regarding DHS data and ethical standards are available at: http://goo.gl/ny8T6X.

\section{Consent for publication}

No consent to publish was needed for this study as we did not use any details, images or videos related to individual participants. In addition data used is available in the public domain.

\section{Competing interests}

The authors declare that they have no competing interests.

\section{Publisher's Note}

Springer Nature remains neutral with regard to jurisdictional claims in published maps and institutional affiliations.

\section{Author details \\ ${ }^{1}$ School of International Development and Global Studies, University of Ottawa, Ottawa, Canada. ${ }^{2}$ Warwick Centre for Applied Health Research and Delivery (WCAHRD), Division of Health Sciences, Warwick Medical School, University of Warwick, Coventry CV4 7AL, UK. ${ }^{3}$ Bloomberg School of Public Health, Johns Hopkins University, Baltimore, MD, USA. ${ }^{4}$ Department of Epidemiology and Medical Statistics, Faculty of Public Health, College of Medicine, University of Ibadan, Ibadan, Nigeria.}

Received: 14 February 2018 Accepted: 23 May 2018

Published online: 31 May 2018

\section{References}

1. Yaya S, Bishwajit G, Shah V. Wealth, education and urban-rural inequality and maternal healthcare service usage in Malawi. BMJ Global Health. 2016;1: e000085. https://doi.org/10.1136/ bmjgh-2016-000085. 
2. WHO, UNICEF, UNFPA, the World Bank and the United Nations population division estimates. Estimates of maternal mortality ratio (MMR, maternal deaths per 100000 live births), number of maternal deaths, and lifetime risk, by United Nations MDG region, 2013.

3. Prata N, Passano P, Sreenivas A, Gerdts CE. Maternal mortality in developing countries: challenges in scaling-up priority interventions. Women's health. 2010;6(2):311-27. https://doi.org/10.2217/whe.10.8. PMID: 20187734

4. The World Factbook. Maternal mortality rate. In: Central intelligence agency; 2010.

5. Alvarez JL, Gil R, Hernandez V, Gil A. Factors associated with maternal mortality in sub-Saharan Africa: an ecological study. BMC Public Health. 2009;9:462. https://doi.org/10.1186/1471-2458-9-462. PMID: 20003411

6. Birmeta K, Dibaba Y, Woldeyohannes D. Determinants of maternal health care utilization in Holeta town, Central Ethiopia. BMC Health Serv Res. 2013; 13:256. https://doi.org/10.1186/1472-6963-13-256. PMID: 23822155

7. Tey NP, Lai SL. Correlates of and barriers to the utilization of health services for delivery in South Asia and sub-Saharan Africa. Sci World J. 2013;2013: 423403. https://doi.org/10.1155/2013/423403. PMID: 24288482

8. Zere E, Kirigia JM, Duale S, Akazili J. Inequities in maternal and child health outcomes and interventions in Ghana. BMC Public Health. 2012;12:252. https://doi.org/10.1186/1471-2458-12-252. PMID: 22463465

9. World Health Organization. Trends in maternal mortality: 1990 to 2010 . Tech. Rep., WHO, UNICEF, UNFPA and The World Bank Estimates. Geneva, Switzerland: 2012

10. Ahmed S, Creanga AA, Gillespie DG, Tsui AO. Economic status, education and empowerment: implications for maternal health service utilization in developing countries. PLoS One. 2010;5(6):e11190. https://doi.org/10.1371/ journal.pone.0011190. PMID: 20585646

11. Fournier P, Dumont A, Tourigny C, Dunkley G, Drame S. Improved access to comprehensive emergency obstetric care and its effect on institutional maternal mortality in rural Mali. Bulletin of the WHO. 2009;87(1):30-8. PMID: 19197402

12. David-Wayas O, Ugbor IK, Arua M, Nwanosike DU. Analysis of inequality in healthcare utilization among pregnant women in Nigeria: concentration index approach. Int'I J of Asian Social Science. 2017;7(5):424-33.

13. Irwin A, Valentine N, Brown C, Loewenson R, Solar O, Brown H, Koller T, Vega J. The commission on social determinants of health: tackling the social roots of health inequities. PLoS Med. 2006;3:e106.

14. Culyer AJ. Equity - some theory and its policy implications. J Med Ethics. 2001;27:275-83.

15. Gwatkin DR, Bhuiya A, Victora CG. Making health systems more equitable. Lancet. 2004;364:1273-80.

16. Gwatkin D, Rutstein S, Johnson K, Suliman E, Wagstaff A, Amozou A. Initial country-level information about socioeconomic differences in health, nutrition, and population. Washington: The World Bank; 2007.

17. Boerma JT, Bryce J, Kinfu Y, Axelson H, Victora CG. Mind the gap: equity and trends in coverage of maternal, newborn, and child health services in 54 countdown countries. Lancet. 2008;371:1259-67.

18. Victora CG, Wagstaff A, Schellenberg JA, Gwatkin D, Claeson M, Habicht JP. Applying an equity lens to child health and mortality: more of the same is not enough. Lancet. 2003:362(9379):233-41.

19. Qian Y, Gao J, Zhou Z, Yan J, Xu Y, Yang X, et al. An equity analysis of health examination service utilization by women from underdeveloped areas in western China. PLOS ONE. 2017;12(10):e0186837.

20. Benin Demographic and Health Survey, 2006 \& 2012

21. Wanjira C, Mwangi M, Mathenge E, Mbugua G, Ng'ang'a Z. Delivery practices and associated factors among mothers seeking child welfare services in selected health facilities in Nyandarua South District, Kenya. BMC Public Health. 2011;11:360

22. Adebowale AS, Palamuleni ME. Modern contraceptive use, sex refusal and spousal difference in level of education among married women in Nigeria: are they interrelated? Int'l I of humanities and. Soc Sci. 2014;4(6):217-30.

23. Babalola S, Fatusi A. Determinants of use of maternal health services in Nigeria-looking beyond individual and household factors. BMC Pregnancy Childbirth. 2009:9:43.

24. Idris SH, Sambo MN, Ibrahim MS. Barriers to utilisation of maternal health services in a semiurban community in northern Nigeria: the clients' perspective. Niger Med J. 2013;54(1):27-32.

25. Mpembeni RN, Killewo JZ, Leshabari MT. Use pattern of maternal health services and determinants of skilled care during delivery in southern
Tanzania: implications for achievement of MDG-5 targets. BMC Pregnancy and Childbirth. 2007;7(1):1.

26. United Nations. Sustainable development goals. Full report of the Open Working Group of the General Assembly on Sustainable Development Goals 2014. https://sustainabledevelopment.un.org/focussdgs.html.

27. Eyob Z, Doyin O, Joses MK, Mwikisa CN. Inequities in skilled attendance at birth in Namibia: a decomposition analysis. BMC Pregnancy \& Childbirth. 2011;1:34.

28. Limwattananon S, Tangcharoensathien V, Prakongsaib P. Equity in maternal and child health in Thailand. Bull World Health Organ. 2010;88:420-7.

29. Daniel $F$, Chunhuei $C$. Health care utilization in Ecuador: a multilevel analysis of socio-economic determinants and inequality issues. Health Pol Plann. 2010;25:209-18.

30. Houweling TA, Kunst AE, Huisman M, Mackenbach JP. Using relative and absolute measures for monitoring health inequalities: experiences from cross-national analyses on maternal and child health. Int J Equity Health. 2007;6:15.

31. Houweling TA, Ronsmans C, Campbell OM, Kunst AE. Huge poor-rich inequalities in maternity care: an international comparative study of maternity and child care in developing countries. Bull World Health Organ. 2007;85(10):745-54. PMID: 18038055

32. Long QA, Zhang TH, Xu L, Tang SL, Hemminki E. Utilisation of maternal health care in western rural China under a new rural health insurance system (new co-operative medical system). Tropical Med Int Health. 2010;15:1210-7.

33. Harris A, Zhou Y, Liao H, Barclay L, Zeng WY, Gao Y. Challenges to maternal health care utilization among ethnic minority women in a resource-poor region of Sichuan Province China. Health Pol Plann. 2010;25:311-8.

34. Simkhada B, van Teijlingen ER, Porter M, Simkhada P. Factors affecting the utilization of antenatal care in developing countries: systematic review of the literature. J Adv Nurs. 2008:61:244-60.

35. Pratley P. Associations between quantitative measures of Women's empowerment and access to care and health status for mothers and their children: a systematic Reviewof evidence from the developing world. Soc Sci Med. 2016;169:119-31.

\section{Ready to submit your research? Choose BMC and benefit from:}

- fast, convenient online submission

- thorough peer review by experienced researchers in your field

- rapid publication on acceptance

- support for research data, including large and complex data types

- gold Open Access which fosters wider collaboration and increased citations

- maximum visibility for your research: over $100 \mathrm{M}$ website views per year

At BMC, research is always in progress.

Learn more biomedcentral.com/submissions 